\title{
Palatal cleft: Results after 18 years, one surgeon, one primary technique
}

\author{
Anthony de Buys Roessingh*, Laurent Medinger, Martin Broome, Georges Herzog, Chantal Zbinden-Trichet, Céline Béguin, Josée \\ Despars, Yohann Robert, Georgios Dimitropoulos and Oumama E1 Ezzi \\ Department of Pediatric Surgery, University Hospital Centre of the Canton of Vaud (CHUV), 1011 Lausanne, Switzerland
}

\begin{abstract}
This study reviews the results after 18 years of our surgery and follow-up for children born in our hospital with a cleft palate (CP). Evaluation of 18-year-old youngsters born with CP, operated at the time by the same surgeon following the same primary surgical procedure (von Langenbeck). We analyzed the files of children born from 1997 to 2001 with a CP and operated in our hospital. Operations were performed by the same surgeon, following the von Langenbeck procedure adapted according to the children's age or weight. The evaluation was based on the results of the primary surgeries, final phonatory results, otorhinolaryngology interventions, maxillofacial surgery, and psychological needs. All syndromic children were excluded. Seventy-nine files from children born with a cleft were reviewed: 34 were taken into consideration and among them five Pierre Robin Sequence (PRS) were removed. Children were operated at a median age of 5,2 months (3-6). Eighteen percent had a fistula, $45 \%$ had grommets, $14 \%$ were operated for a pharyngeal flap following the Sanvenero-Rosselli technique to improve the phonatory score. Thirty-six (36) percent had a final phonation I, 32\% a phonation I/II and 32\% a phonation IIb. None had an osteotomy. All children were seen by our psychologist. A median of 5.5 multidisciplinary consultations were affected with a median number of general anesthesia of 2.4 (1-6).
\end{abstract}

This retrospective study is based on one primary surgical technique used by the same surgeon. It shows that the von Langenbeck procedure done at six months entails a certain risk of fistula but shows good long-term phonatory results. The number of grommets used is low and must be seen in relation with otitis media and our follow-up. A few complements to our investigations and follow-up are proposed concerning grommets, surgical procedures, and sleep disorder.

\section{Introduction}

A facial cleft can be labial, labio-maxillary (unilateral or bilateral), labio-maxillary-palatal (unilateral or bilateral), or isolated palatal (CP) (Figure 1). CP is present in $25 \%$ to $40 \%$ of all types of cleft, twice as frequent in girls, and with a higher incidence in poor social conditions $[1,2]$. Breast-feeding is functionally impossible for a newborn with a $\mathrm{CP}$ because the lack of palatal muscle entails a lack of the strength of suction ${ }^{3}$. Even if the baby is strong at birth, it may be exhausted after a few days, unable to suck and consequently losing weight. This is particularly true for babies born with a Pierre Robin sequence (PRS), because of respiratory difficulties [3,4]. Palatal or feeding plates may help feeding, even though there is no proof of their efficacy.

Children with a CP are more likely to have secretory otitis media (SOM) and the associated transitory hearing loss that can interfere with language acquisition [5,6]. Their hearing should be evaluated early and regularly. The hearing loss caused by SOM can be persistent or recurrent, variable in degree, and affect one or both ears. In the long term, children with a $\mathrm{CP}$ are at risk of severe speech problems due to velopharyngeal insufficiency (VPI); they should be followed with frequent and specific speech and language evaluations [7]. Studies have shown that children born with a cleft involving both the soft and hard palate have a less favorable speech outcome than children born with a soft palate cleft only [8]. A secondary pharyngeal flap is more often necessary for children with a cleft involving both the hard and soft palate (23\%) than for those with only a soft palate cleft (10\%) [9].

In developed countries, a multidisciplinary team includes several specialists who will handle the various problems of children born with a cleft and follow each child throughout each developmental stage. This is why the handling of a cleft starts at the time it is diagnosed, ideally before birth, and ends when the child is fully grown [10]. It requires the collaboration of obstetricians and genetician's. The concept of the multidisciplinary team is essential for the good and correct followup of the child born with a cleft, and of his family. The objective of the group is to bring together specialists in rehabilitation to optimize the care and the treatment in all fields: functional, oral, esthetic, and psychological. Only a multidisciplinary team can be fully efficient in helping children and their families, by offering optimal care according to priorities and demands [11-13].

The sequelae of CP surgery done normally between three months and 15 months of age concern specifically speech acquisition and hearing capacity. The evaluation of these sequelae is complicated by the heterogeneity within the groups of children, the existence of associated anomalies, the different timing, and surgical techniques of primary palatoplasty, the difference in speech therapy follow-up.

This retrospective study considers the long-term results of one primary surgical technique by one senior surgeon with the same type of evaluation.

${ }^{\star}$ Correspondence to: Anthony de Buys Roessingh, Department of Pediatric Surgery, University Hospital Centre of the Canton of Vaud (CHUV), 1011 Lausanne, Switzerland, Tel: + 41 (0)79 55637 67, Fax: 41 (0)21 31431 02; E-mail: Anthony.Debuys-roessingh@chuv.ch

Key words: cleft palate, speech, grommets, psychological support

Received: April 02, 2020; Accepted: April 17, 2020; Published: April 20, 2020 


\section{Methods}

We identified all children born with a CP between 1997 and 2001. Children born with associated malformations or chromosomal abnormalities were excluded from the study. All children born with $\mathrm{CP}$ were fitted with a removable palatal appliance before one week of age and were bottle fed with a normal teat and expressed breast milk. A pediatrician followed the children to evaluate their psychomotor development.

Our multidisciplinary cleft team was composed of the pediatric surgeon, two pediatric ENT specialists, a craniofacial surgeon, an orthodontist, two speech therapists and a psychologist. Obstetricians and geneticians were also present at various times during the followup. All children were assessed by the pediatric surgeon before and after surgery, six months later, and once a year until the age of three and a half. When the child reached one year of age, parents were provided with strategies to encourage babbling and early verbal communication. From the age of three and a half, the child was evaluated by a multidisciplinary team (Table 1).

A palatal plate made of acrylic resin was made one day after birth; rigid for its outer part, and softer and more flexible for the inner layer that is in contact with the mucosa (Figure 2). It required the making of an impression by the orthodontist, usually at the hospital, as soon as possible after birth so that its shape would perfectly match that of the palate $[14,15]$.

Velo-palatoplasty was done at six months. After the usual installation of the child in the operating room, incisions were made along each margin of the cleft as far as the half-uvulae to create two flaps (Figure 3). The hamulus on each side was then broken with a Trélat elevator to relax the tendon of the velo-palatine tensor. One then proceeded to the undermining, with the tissues being pushed back and carefully divided until the detachment of the soft palate was completed. The mucosa that lines the nasal sides of the palatal shelves was easy to detach by displacing the velum towards the inside. This procedure created two layers. When direct suturing was not possible, a nasal layer using vomerine mucosa was used. A longitudinal incision was made in the lower edge of the vomerine mucosa and nasal mucosa, on either side, from front to back, and was then sutured [16,17]. Large dissection of the palate was discouraged: it does create scars and retraction with retrognathia. If the hard palate was completely open, a longitudinal incision divided the border of the cleft and continued forward up to

Table 1. Basic general follow-up of children with a cleft palate (CP)

\begin{tabular}{|l|l|l|}
\hline When? & What? & Who? \\
\hline Antenatal & $\begin{array}{l}\text { Information } \\
\text { Psychological help } \\
\text { Genetic counseling }\end{array}$ & $\begin{array}{l}\text { Paediatric surgeon } \\
\text { Psychologue }\end{array}$ \\
\hline Birth & $\begin{array}{l}\text { Information } \\
\text { Alimentary problems }\end{array}$ & $\begin{array}{l}\text { Paediatric surgeon } \\
\text { Nurse } \\
\text { Orthodontist (plaque) }\end{array}$ \\
\hline 6 months & Primary surgery & Paediatric surgeon \\
\hline 6 months -3 years & $\begin{array}{l}\text { Check-up } \\
\text { Parental guidance }\end{array}$ & $\begin{array}{l}\text { Pediatric surgeon } \\
\text { ENT, pediatrician } \\
\text { Orthophonist }\end{array}$ \\
\hline 3 years & Bilan & Team \\
\hline 3-9 years & $\begin{array}{l}\text { Follow-up } \\
\text { Guidance (speech) } \\
\text { Secondary surgery: fistula, pharyngoplasty }\end{array}$ & $\begin{array}{l}\text { Team } \\
\text { Pediatric surgeon }\end{array}$ \\
\hline 7-9 years & Orthodontist & Team \\
\hline 12-18 years & $\begin{array}{l}\text { Follow-up } \\
\text { Osteotomy }\end{array}$ & $\begin{array}{l}\text { Team } \\
\text { maxillo-facial surgeon }\end{array}$ \\
\hline 18-20 years & Genetic counselling & Team \\
\hline
\end{tabular}
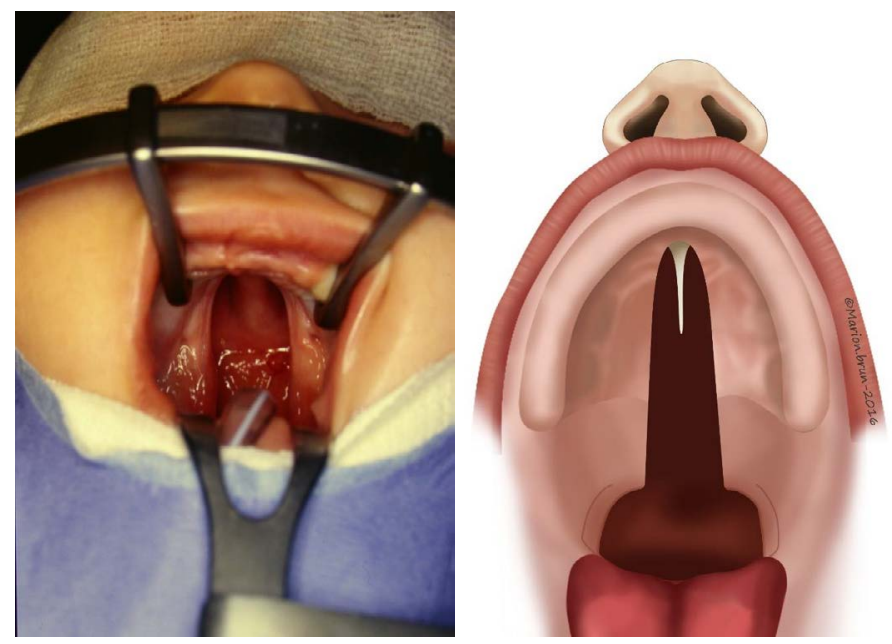

Figure 1. Cleft palate (view and schema).

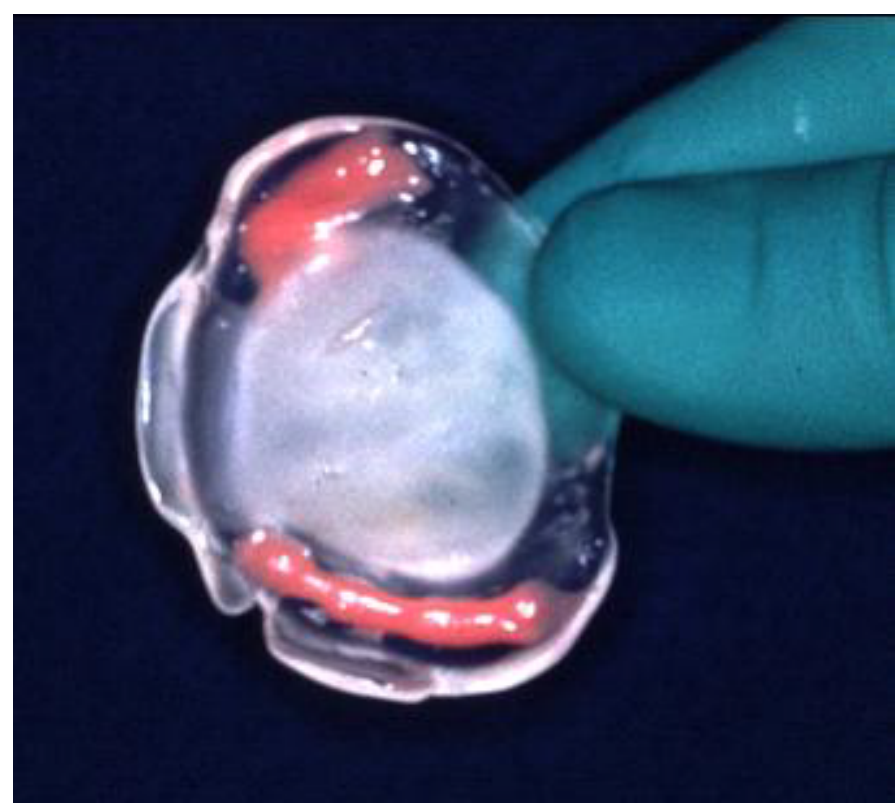

Figure 2. Removable palatal appliance.
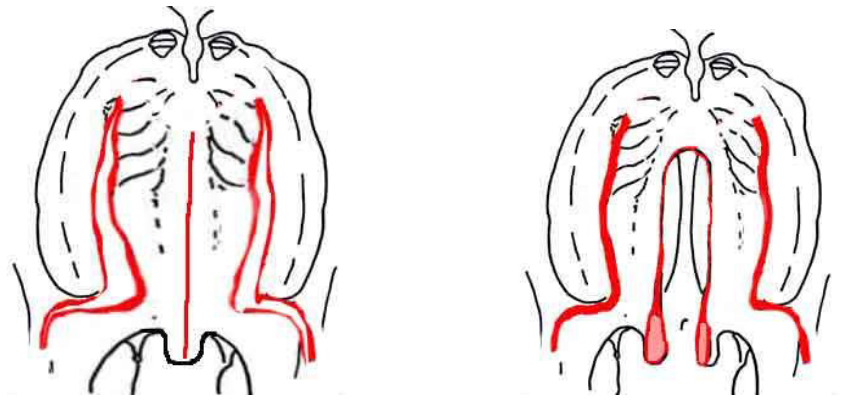

Figure 3. Surgical incisions for the palatal repair (von Langenbeck procedure).

the apex of the cleft. Two flaps without incision behind the maxillary tuberosity or alveolar arch were simply done.

Hearing assessment was performed at variable ages and in response to individual needs over the following years. Hearing was checked once a year by the ENT specialist. Pediatricians were instructed in the special care needed to diagnose chronic SOM and the risk of hearing loss in 
their cleft patients. They were asked to perform routine otoscopy, tympanometry, and check for glue ear. Hearing evaluation was also reported in a reproducible manner with impedance tympanograms, using a Grason-Stadler GSI-28A tympanometer and total audiograms using a Grason-Stadler GSI-16 earphone audiometer (Grason-Stadler, Littleton, MA, USA). These completed the ENT's clinical examination and were performed on the same day as the speech evaluation. Grommets were inserted at the time of the palatoplasty, if needed.

Perceptual speech evaluation by qualified speech pathologists experienced in cleft pathology is the mainstay of speech evaluation in our institution. The evaluations were made separately by the two therapists. Standard upper airway assessments were documented, including the presence or absence of snoring, mouth breathing, apnea, and nasal airway obstruction. VPI or nasal air emission was evaluated according to the Borel-Maisonny classification (Table 2). Hyper-nasality, hypo-nasality, audible nasal emission, voice quality, misarticulations associated with VPI and intelligibility were assessed (Table 3) [18]. Nasal emission on separate phonemes was measured using a 622 Kay Electronics nasometer (Kay Elemetrics, Pine Brook, NJ, USA). VPNE was used from time to time, especially before pharyngeal flap surgery, but not on a regular basis. Fluoroscopic velopharyngeal evaluations were not considered. Clinical perceptual speech evaluations and nasometry were performed by the same two therapists before and after the operations. Articulation problems such as simplification, replacement, or deletion of consonants, were also recorded. The presence of nasal, pharyngeal or glottal articulation led to automatic classification as a type $2 / 3$ articulation score. Children with type 1/2 Borel-Maisonny score or worse were referred to a speech therapist near their home and were seen by the university hospital's specialist once a year to evaluate progress.

All oro-nasal fistulas were closed before five years of age if the children/parents expressed a social discomfort due to liquid coming through the nose ("Jetage") or in a case of speech repercussion. The technique of closure of the fistula was based on the elevation of the mucoperiosteum of the entire palate. Closure of the fistula was postponed for as long as possible, to minimize adverse consequences on the growth of the maxilla.

The criteria for recommending pharyngeal flap surgery were based on perceptual analysis: hypernasality, weak pressure consonants, weak pharyngeal musculature, and nasal emission (type 2, 2/3 BorelMaisonny). All fistulas were closed prior to, or concomitantly with, pharyngeal flap surgery. In primary VPI, the palate was described in terms of its length and mobility, both of which were abnormal in most cases. Cranial-based pharyngeal flaps (Figure 4) were performed according to Schönborn and Sanvenero-Rosselli [19,20]. A broad, cranially based pharyngeal flap was incised and elevated from the prevertebral fascia to be sutured to the nasal side of the incised velum. The donor site was closed directly. The soft palate was dissected, and two mucosal flaps prepared. The two mucosal flaps were incised on

Table 2. Borel-Maisonny classification for the phonation

\begin{tabular}{|c|c|}
\hline Type O & No phonation \\
\hline Type 1 & Excellent phonation, no nasal air emission \\
\hline Type $1 / 2$ & Good phonation, intermittent nasal air emission, good intelligibility \\
\hline Type 2 & Phonation with continuous nasal emission, \\
\hline Type $2 b$ & $\begin{array}{l}\text { Phonation with continuous nasal emission but good intelligibility and no } \\
\text { social discomfort }\end{array}$ \\
\hline Type $2 \mathrm{M}$ & Phonation with continuous nasal emission, bad intelligibility \\
\hline Type $2 / 3$ & $\begin{array}{l}\text { Phonation with continuous nasal emission with compensatory articulation, } \\
\text { bad intelligibility }\end{array}$ \\
\hline
\end{tabular}

Table 3. Compensatory phenomenon related or not related to velopharyngeal insufficiency (VPI)

\begin{tabular}{|l|l|l|l|l|}
\hline $\begin{array}{l}\text { Simple misarticulation, } \\
\text { not related to VPI }\end{array}$ & $\begin{array}{l}\text { Heavy } \\
\text { misarticualtion }\end{array}$ & $\begin{array}{l}\text { Voice } \\
\text { trouble }\end{array}$ & $\begin{array}{l}\text { Compensatory } \\
\text { movements }\end{array}$ & $\begin{array}{l}\text { Added } \\
\text { sounds }\end{array}$ \\
\hline Sigmatisms & $\begin{array}{l}\text { Articualtions } \\
\text { compensation }\end{array}$ & $\begin{array}{l}\text { Hpo- } \\
\text { nasality }\end{array}$ & $\begin{array}{l}\text { Facial } \\
\text { (Syncinesia) }\end{array}$ & Snoring \\
\hline Posterioriations & Glottic sounds & $\begin{array}{l}\text { Hyper- } \\
\text { nasality }\end{array}$ & & $\begin{array}{l}\text { Mouth } \\
\text { breathing }\end{array}$ \\
\hline Deletion of consonants & Raucity & Raucity & & Clics \\
\hline $\begin{array}{l}\text { Confusions Fricative } \\
\text { sounds } \\
\text { Confusions oral nasal } \\
\text { Backing }\end{array}$ & & & & \\
\hline
\end{tabular}
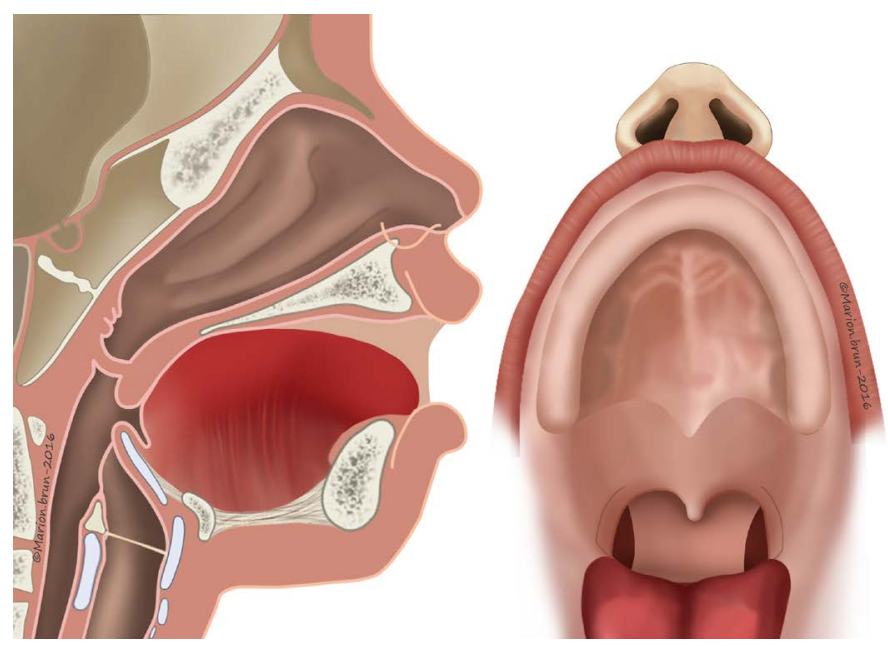

Figure 4. Cranial-based pharyngeal flaps according to Schönborn and Sanvenero-Rosselli $[19,20]$.

the dorsal velar side. The pharyngeal flap, including its muscle layer, was sutured to the nasal mucosa of the velum. In the midline, the two buccal flaps were joined and sutured in their entire thickness to the surface of the flaps.

Surgical success was measured by nasoendoscopy in terms of elimination of perceptible hypernasality or oral resonance and instrumental evidence of complete velopharyngeal closure. Velopharyngeal assessment was performed at six and 12 months after surgery. Surgical failure was defined in terms of persistent hypernasality and/or nasal turbulence and of incomplete velopharyngeal closure evidenced by nasometry at least six months after surgery.

An objective determination of the need for orthognathic surgery is based on the data available from the analysis of the lateral cephalograms: the anteroposterior relationship of the maxillary basal arch to the anterior cranial base uses the SNA, SNB, ANB angles ( $\mathrm{S}=$ sella, $\mathrm{N}=$ nasion, $\mathrm{A}=$ subspinal, $\mathrm{B}=$ supramental). Anteroposterior jaw dysplasia can be measured according to the Wits appraisal (perpendiculars from points $\mathrm{A}$ and $\mathrm{B}$ onto the occlusal plane), but the distance from the upper lip to the e-plane (line drawn from the tip of the nose to the chin) is the most used criteria. Children with poor facial aesthetics were considered for an orthognathic correction even when the lateral cephalogram was satisfactory. The basis for this decision is mostly subjective and a matter for a family discussion.

A psychological support for the parents was instituted from the very moment the prenatal diagnostic was established and maintained until the child reached the age of 20 [21,22]. Neonatal discussions were organized to provide information about the cleft and its consequences. Feeding problems were discussed, and the parents were informed that 
breast-feeding would be impossible in terms of efficacity. The difficulties in language development, and the nature and schedule of the surgery to be expected, were also discussed. Later discussions were organized for both children and parents to provide the support needed if the social integration of the child/adolescent was affected, with resulting manifestations of anxiety, poor self-esteem, or depression $[23,24]$. This psychological support was offered if the child and/or the family were seen to need it, and kept up until the age of 20 . The psychologist was present during all multidisciplinary consultations.

\section{Results}

Seventy-nine files of children born with a cleft were reviewed: 29 were considered for CP (without chromosomal abnormalities or PRS). Children were operated at a median age of 5,2 months (3-6) for CP.

Primary surgery on the $29 \mathrm{CP} / \mathrm{PRS}$ cases followed the von Langenbeck technique (Figure 3). Eighteen percent had a fistula after the surgery; its closure required one operation per child.

The ENT follow-up revealed that $45 \%$ needed grommets, the placement of which required several operations in $60 \%$ of the children concerned. The indication for grommets was more frequently based on clinical observation than on microscope examination. As pediatricians were instructed to regularly check their cleft patients for chronic serous otitis media, with its ensuing risk of hearing loss, 20 children did not undergo an ENT control before the age of three, at the time of the first multidisciplinary consultation.

Secondary surgery was necessary in $14 \%$ for a pharyngeal flap following the Sanvenero-Rosselli technique, three at the age of 16, and two at the age of seven. Post-operative complications in one case required a secondary opening of the left port due to symptomatic blockage of the nasal passage during sport activities. And last, a minor lateral cutback of the flap was performed six months after the initial pharyngoplasty and symptoms resolved promptly with no effect on phonation.

Concerning the sleep obstructive apnea syndrome (SOAS) before and after surgery, parents of the children were asked if they had noted any snoring during the night or tiredness during the day. Polygraphic monitoring was carried out on eight children before surgery but not routinely after the pharyngoplasty.

A final phonatory scoring shows that thirty-six (36) percent have a normal phonation with no nasal air emission (phonation I), $32 \%$ have a good phonation with intermittent nasal air emission but good intelligibility (phonation I/II) and 32\% a phonation with continuous nasal emission but good intelligibility and no social discomfort (phonation IIb). No child developed any compensatory phenomenon (Table 4).

All children were seen by the maxillo-facial surgeon and the orthodondist jointly during each multidisciplinary consultation.

Table 4. Final results of the 29 children born with a CP

\begin{tabular}{|l|c|l|l|}
\hline Median age of surgery & \multicolumn{2}{|c|}{5.2 months } & \\
\hline Percentage of oro-nasal fistula & $18 \%$ & & \\
\hline Percentage use of grommets & $45 \%$ & & \\
\hline $\begin{array}{l}\text { Percentage of pharyngoplasty } \\
\text { needed }\end{array}$ & $14 \%$ & & \\
\hline $\begin{array}{l}\text { Final phonatory scores } \\
\begin{array}{l}\text { Median number of consultations } \\
\text { I }\end{array}\end{array}$ & $\begin{array}{c}5.5 \\
\text { I phation }\end{array}$ & $\begin{array}{c}32 \% \text { phonations } \\
\text { I/II }\end{array}$ & $\begin{array}{c}32 \% \text { phonation } \\
\text { IIb }\end{array}$ \\
\hline Median number of anaesthesia & $2.4(1-6)$ & & \\
\hline
\end{tabular}

Indications for surgery were discussed in terms of functional need and esthetic self-esteem. The median number of general anesthesia was 2.4 (1-6). None had an osteotomy.

Psychological support was offered to the parents in all cases as soon as the diagnosis was established, prenatally or after birth. The surgeon saw the 34 parents the day of birth or the day after, even when the hospital where the child was born was situated in another part of the country. A psychological consultation offered by a specialist to all parents on the first day after the birth was accepted in $70 \%$ of the cases, and during each pluridisciplinary consultation in $94 \%$ of the cases.

A median of 5.5 multidisciplinary consultations were organized for children after the age of three and their families (Table 4).

\section{Discussion}

This retrospective study based on one primary surgical technique for CP used by the same surgeon shows that the von Langenbeck procedure done at six months entails a risk of fistula (19\%) but obtains good long-term phonatory scores, even though $15 \%$ of the children required a pharyngoplasty. The number of grommets used for SOM was low, possibly due to our good ENT follow-up. There were no surgical interventions on mandibular or maxillary bone. All parents needed psychological support after the diagnosis of CP.

Facial cleft is present in one of 750 births, and its prevalence seems to vary between different ethnic groups. The causes of facial cleft are far from being understood and may be multiple. But some clefts appear to be related to genetic and environmental factors [25]. A diagnosis of facial cleft can be made as early as the $12^{\text {th }}$ week of gestation, but it is usually made at 20 weeks; CP's are difficult to diagnose, especially if they are not looked for. The announcement of the diagnosis is extremely delicate and must be made with tact, especially in the matter of the words used. In numerous cases, an antenatal diagnosis of $\mathrm{CP}$ enables many future parents to better prepare themselves to confront and accept the malformation of the baby they are expecting [10].

The concept of the multidisciplinary team is essential for the good and correct follow-up of the child born with a cleft, and of his family. The objective of the group is to bring together specialists in rehabilitation to optimize the care and the treatment in all fields.

Our team finds that a feeding plate may have several advantages, even if they are not actually proved: it facilitates bottle feeding but not breast-feeding, maintains the tongue in a normal position, allows the full growth potential of the maxilla by preventing the tongue from getting into the cleft, protects the sutures that close the palatal cleft after surgery and, last but not least, gives confidence to the parents [14].

The timing of the operation on children born with a CP may vary largely, depending on the local school of surgery and historical teaching. Surgery on the palatal cleft must be done before 18 months of age to facilitate language acquisition; results in term of phonation are very poor when surgery is performed after this age [26]. Staphylorraphy is a perfectly reliable conventional technique which allows the closure of the palatal cleft: but it does create scars and retraction with retrognathia [16]. The Furlow technique [27] offers a different version of the Z-plasty and makes it possible to lengthen the soft palate. This surgery is based on the retrodisplacement of the velar muscles, primarily the levator veli palatini. It rests on the intravelar dissection of the muscle fibers, which are then directly sutured end to end to reconstruct a muscle sling. It implies an extensive dissection of the muscles, which strikes us as a source of fibrosis. It lengthens the soft palate without 
using the mucoperiosteum, a factor favorable to satisfactory growth, and it allows a better muscular suture which does not impair velar contraction. Intravelar dissection has been realized for twelve years in our institution: the mucosa that lines the nasal sides of the palatal shelves are detached by displacing the velum towards the inside; this procedure creates two layers, one in the oral cavity and one in the buccal cavity, and in between the muscles are free, put horizontally and fixed together [28]. The aim of this dissection is to improve speech development by placing the muscle in a horizontal position lengthening by this way the palate.

Fistulas of the palate remain the major early complication after primary palate closure. These fistulas do not appear to be linked exclusively to a defective surgical technique. While a weakness of the sutures may obviously be a contributing factor, a single layered closure of the nasal mucosa on the bony vault may make fistulas more likely. A second layer of closure on the oral side should significantly reduce the incidence of fistulas but does not eliminate them all together. The first consequence of a fistula is the leakage of fluids or soft food such as milk or water through the nose. It is known as the "signe du chocolat" when chocolate food falls from the nostril. The passage of food through the nostril can also result from a too short or scarred soft palate. The second consequence is a speech disorder, called rhinolalia, meaning air coming through the nose during speech. The speech therapist must distinguish between VPI and air coming from the mouth through the fistula. Indication for closure of a fistula depends on the severity of its consequences, but the child must be followed by the speech therapist to be sure that compensatory phenomena due to the leakage of air are not present (Table 3). A technique for closure of the fistula is based on the elevation of the mucoperiosteum of the entire palate. Simple closure of the hole is just not possible. Closure of the fistula must be postponed as long as possible in order to minimize adverse consequences on the growth of the maxilla.

Due in part to velopharyngeal dysfunction and problems such as SOM, children born with a CP have significantly more speech and hearing problems than children born without a cleft $[10,29]$. The high prevalence of SOM and its associated hearing loss due to the presence of fluid in the middle ear (glue ear) may affect the development of speech and language and lead to lower verbal activity $[5,9,30]$. The surgical insertion of a tympanostomy/ventilation tube (grommet) allows the fluid to drain, and thus provides aeration and equalization of pressure in the middle ear cavity. This explains why children with cleft palate and grommets have better language acquisition and prognosis than the children with cleft palate and no grommets $[31,32]$.

Tympanometry has been the most common and widely accepted tool for assessing the presence of fluid in the middle ear. It seems to have a high degree of sensitivity and a good specificity for detecting SOM [33,34]. In our case, since the decision to insert grommets was taken mainly on the basis of the pediatric controls, a difficult diagnosis which may not always be very accurate, we found that our percentage of grommets was very low, much lower than in the literature. We have therefore improved our own ENT controls: all ears of children with CP are now checked during the primary surgery with a microscope and under anesthesia, and in case of a visualized glue ear grommets are inserted after a paracentesis. About 90 percent of children now have grommets for glue ear.

However, the possible technical complications of their insertion must also be taken into consideration, for instance perforation, tympanic membrane scarring (tympanosclerosis) and cholesteatoma.
Kay and al. noted that the incidence of tympanic membrane perforation was higher after repeated tube insertions, after grommet insertion at a young age, and with the use of a long-stay tube [34]. Goudy et al. [5] found a $25 \%$ incidence of conductive hearing loss and a $5.9 \%$ incidence of cholesteatoma following the insertion of grommets in cleft palate patient. For Shapiro et al. [35], the incidence of tympanic perforation related to the insertion of grommets in children with cleft palate is about $64 \%$.

Children with a CP are at risk of severe speech problems and should be followed with frequent and specific speech and language evaluations $s^{36}$ Evaluation of speech can be done subjectively by perceptual evaluation (human judges) or measured by pressure-flow technology. In Frenchspeaking countries, the reference for the evaluation of speech or nasal air emission is usually the "old" Borel-Maisonny classification (Table 1) [18]. We also used routine nasometry, even though the results may depend on the child's physical (tired, attentive, or not) and psychological (intimidated, tense, or relaxed) state. Video nasopharyngeal endoscopy (VNPE) is a technique that allows direct observation of velopharyngeal movement during speech. It requires the cooperation of the child and its interpretation can be subjective or operator dependent. VNPE as a systematic pre-surgery work-up was only introduced in our centre in 1999, and so most of the children operated on before this date lacked this important aspect of their evaluation. We think that VNPE should be performed, in that it provides important information for tailoring the flap to the individual anatomy. Cinefluoroscopy gives a dynamic visualization of the velopharynx but involves high radiation exposure and is not done in our institution.

Exercises to strengthen the velopharyngeal muscles can be performed with children as young as 12 months ("guidance"). Ageappropriate games and increased parental awareness of their active role in speech acquisition can improve breath control and correct positioning of the tongue and lips early. Speech therapy sessions can only do so much, and regular daily exercises at home must complete the treatment [37].

Continued speech therapy is mandatory after the surgery to improve the mobility and strength of the velopharyngeal muscle complex. If speech therapy is unsuccessful, velopharyngeal dysfunction can be treated prosthetically or surgically [38]. The criteria for recommending surgery are based on perceptual analysis: hypernasality, weak pressure consonants, weak pharyngeal musculature, and nasal emission. Surgical procedures include the enlargement of the posterior pharyngeal wall with various injectable materials, the lengthening of the palate by pushback palatoplasty and ppharyngeal flap, sphincter pharyngoplasty or pharyngeal flap alone [39-43]. Pharyngeal flaps can be based superiorly, inferiorly, or laterally [20]. Indications for surgery must take into account the social impact of the child's speech, and also the age of the child as the recovery period is quite uncomfortable. Since 2014, pharyngoplasties have been realized with a push-back of the entire palate and the use of a superior pharyngeal flap to be really efficient. In our study, all children had a simple superior pharyngeal flap. Speech controls after a pharyngoplasty are mandatory and must be done by the speech therapist. We usually wait six months after the surgery. The failure of this surgery is obvious when hypernasality persists. It can be the result of surgical error, such as a too narrow flap or a poor short flap; but the flap could also be too broad, causing hyponasal speech and SAOS. Barot et al. [44], reported that $15 \%$ of patients who had undergone pharyngeal flap surgery for velopharyngeal dysfunction over a 9-year period required revision. Witt et al. [45], described the same results in children who had received 
a velopharyngeal flap or sphincter pharyngoplasty. Post-surgery examinations are necessary to check for nasal obstruction that persists after one month and for sleep apnea. Preoperative assessment with videoendoscopy of the velopharyngeal mechanism can be very useful in choosing which type of pharyngeal flap will best assist closure of the velopharyngeal port during speech. In our institution this assessment is now made before the surgery. Concerning the evaluation of SAOS, we now do a polygraphy before the pharyngoplasty, and after a few months. Symptoms including fitful sleep, unresolved snoring, daytime fatigue are useful for a clinical evaluation but not sufficient to diagnose an SAOS. They must be investigated carefully and discussed case by case.

Orthognathic surgery to correct facial disharmony is part of the normal follow-up of children born with CP. When planning corrective surgery, many factors, such as facial profile, intermaxillary discrepancies and dento-alveolar relationship, are considered. An objective determination of the need for orthognathic surgery may be based on the data available from the analysis of the lateral cephalograms as described before. Children with poor facial aesthetics despite a more favourable lateral cephalogram may also be considered for an orthognathic correction. The decision is mostly subjective and a matter for a family discussion $[46,47]$.

The diagnosis of CP was given after the birth to all the families in the study. But the literature shows that most parents wish to be informed of an expected defect of the baby as early as possible, in order to learn to face the reality of the problem $[10,48]$. We must therefore improve our antenatal diagnosis of CP. Later, the child himself will also be affected, with resulting manifestations of anxiety, poor self-esteem, or depression. The psychological consultation offered by specialists during each pluridisciplinary consultation helps to spot risky situations and to set up a program of support adapted to each individual child.

\section{Conclusion}

This retrospective study presents the results of one technique applied by one confirmed surgeon. It shows that the von Langenbeck dissection of the palate, even if it does entail a risk of palatal fistula, nevertheless has good long-term functional, esthetic and phonatory results. However, the results of this study has led us to adopt a few complements to our investigations and follow-up: the children's ears are all checked with a microscope to determine the need for grommets; intravelar dissection is performed during each primary surgery to improve speech development; investigation of the type of pharyngoplasty to be adopted is done with videoendoscope to be more precise in term of surgical choice; SAOS is always checked for before and after surgery in order to investigate airway flow; and pharyngoplasty is done with a "push-back" of the palate to improve its efficiency.

\section{References}

1. Persson C, Elander A, Lohmander-Agerskov A, Söderpalm E. Speech outcomes in isolated cleft palate: impact of cleft extent and additional malformations. Cleft Palate Craniofac 34: 397-408. [Crossref]

2. Hagberg C, Larson O, Milerad J (1998) Incidence of cleft lip and palate and risks of additional malformations. Cleft Palate Craniofac J 35: 40-45. [Crossref]

3. Baudon JJ, Renault F, Goutet JM, Véronique Soupre V, Gold F, Marie-Paule Vazquez MP (2002) Motor dysfunction of the upper digestive tract in Pierre Robin sequence as assessed by sucking-swallowing electromyography and esophageal manometry. $J$ Pediatrics 140: 719-723. [Crossref]

4. Myer CM, Reed JM, Cotton RT, Willging JP, Shott SR (1998) Airway management in Pierre Robin Sequence. Otolaryngol Head Neck Surg 118: 630-635. [Crossref]

5. Goudy S, Lott D, Canady J, Smith RHJ (2006) Conductive hearing loss and otopathology in cleft palate patients. Otorhinolaryngol Head and Neck Surg 6: 946948. [Crossref]
6. Flynn T, Möller C, Jönsson R, Lohmander A (2009) The high prevalence of otitis media with effusion in children with cleft lip and palate as compared to children without clefts. Int J Pediatr Otorhinolaryngol 73: 1141-1446. [Crossref]

7. Persson C, Elander A, Lohmander-Agerskov A, Söderpalm E (2002) Speech outcomes in isolated cleft palate: impact of cleft extent and additional malformations. Cleft Palate Craniofac J 39: 397-408. [Crossref]

8. Lohmander-Agerskov A, Havstam C, Söderpalm E, Elander A, Lilja S, et al. (1993) Assessment of speech in children after repair of isolated cleft palate. Scand J Plast Reconstr Surg Hand Surg 27: 307-310. [Crossref]

9. Marrinan EM, LaBrie RA, Mulliken JB (1998) Velopharyngeal function in nonsyndromic cleft palate: relevance of surgical technique, age at repair, and cleft type. Cleft Palate Craniofac J. 35: 95-100. [Crossref]

10. Rey-Bellet C, Hohlfeld J (2004) Prenatal diagnosis of facial clefts: evaluation of a specialised counselling. Swiss Med Wkly 134: 640-644. [Crossref]

11. Herzog G (2011) Psychological impact and antenatal diagnosis on the future parents. Triton Printers.

12. Stock NM, Feragen KB (2016) Psychological adjustment to cleft lip and/or palate: A narrative review of the literature. Psychol Health 31: 777-813. [Crossref]

13. Bezerra JF, Oliveira GH, Soares CD, Cardoso ML, Ururahy MAG, et al. (2015) Genetic and non-genetic factors that increase the risk of non-syndromic cleft lip and/or palate development. Oral Dis 21: 393-399. [Crossref]

14. Müller-Hagedorn S, Buchenau W, Arand J (2017) Treatment of infants with syndromic Robin sequence with modified palatal plates: a minimally invasive treatment option. Head Face Med 13: 4. [Crossref]

15. Herzog G (2011) Feeding the baby. Triton Printers.

16. Malek R (2000) First stage: early primary veloplasty. pp: 139-142.

17. Morris HL, Bardach J, Ardinger H, Jones D, Kelly KM, et al. (1993) Multidisciplinary treatment results for patients with isolated cleft palate. Plast Reconstr Surg 92: 842851. [Crossref]

18. Borel-Maisonny S (1975) Velar insufficiency, point of view of the speech therapist Reeduc Orthophon 13: 61-81.

19. Sanvenero-Rosselli G (1961) Palatal plastic surgery using Langenbeck's pharyngea flaps. Arch Klein Chir 56: 295.

20. Fischer-Brandies E, Nejedlo I (1991) A modification of the Sanvenero-Rosselli velopharyngoplasty. J Craniomaxillofac Surg 1: 19-21. [Crossref]

21. Hunt O, Burden D, Hepper P, Johnston C (2005) The psychosocial effects of cleft lip and palate: a systematic review. Eur J Orthod 27: 274-85. [Crossref]

22. Berger ZE, Dalton LJ (2009) Coping with a Cleft: Psychosocial Adjustment of Adolescents with a Cleft Lip and Palate and Their Parents. Cleft Palate Craniofac $J$ 46: 435-43. [Crossref]

23. Berger ZE, Dalton LJ (2011) Coping with a Cleft II: Factors Associated with Psychosocial Adjustment of Adolescents with a Cleft Lip and Palate and Their Parents. Cleft Palate Craniofac J 48: 82-90. [Crossref]

24. Ward JA, Vig KWL, Firestone AR, Mercado A, et al. (2012) Oral Health-Related Quality of Life in Children With Orofacial Clefts. Cleft Palate Craniofac J 50: 174-181. [Crossref]

25. Bezerra JF, Oliveira GH, Soares CD, Cardoso ML, Ururahy MAG, et al. (2015) Genetic and non-genetic factors that increase the risk of non-syndromic cleft lip and/or palate development. Oral Dis 21: 393-399. [Crossref]

26. de Buys Roessingh AS, Dolci M, Zbinden-Trichet C, Bossou R, Meyrat BJ, et al. (2012) Success and failure for children born with facial cleft in Africa: a 15-year follow-up. World J Surg 36: 1963-1969. [Crossref]

27. Furlow LT Jr. (1986) Cleft palate repair by double opposing Z-plasty. J Plast Reconstr Surg78: 724. [Crossref]

28. Sommerlad BC, Mehendale FV, Birch MJ, Sell D, Hattee C, et al. (2002) Palate rerepair revisited. Cleft Palate Craniofac J 39: 295-307. [Crossref]

29. Becker M, Svenson H, Sarnäs KV, Jacobsson S (2002) Von Langenbeck or Wardill procedures for primary palate repair in patients with isolated cleft palate-speech results. Scand J Plast Reconstr Surg Hand Surg 34: 27-32. [Crossref]

30. Shaw R, Richardson D, McMahon S (2001) Conservative management of otitis media in cleft palate. J Craniomaxillofac Surg 31: 316-320. [Crossref] 
31. Doyle WJ, Reilly JS, Jardini L, Rovnak S (1986) Effect of palatoplasty on the function of the eustachian tube in children with cleft palate. Cleft Palate J 23: 63-68. [Crossref]

32. El Ezzi O, Herzog G, Broome M, Trichet-Zbinden C, Hohlfeld J, et al. (2015) Grommets and speech at three and six years in children born with total cleft or cleft palate. Int J Pediatr Otorhinolaryngol 79: 2243-2247. [Crossref]

33. Watters GWR, Jones JE, Freeland AP (1997) The predictive values of tympanometry in the diagnosis of middle ear effusion. Clin Otolaryngol 22: 343-345. [Crossref]

34. Kay DL, Nelson M, Rosenfeld RM (2001) Meta-analysis of tympanostomy tube sequelae. Otolaryngol. Head and Neck Surg 124: 374-380. [Crossref]

35. Shapiro S (1998) Otologic findings of an Inuit population of cleft palate children. $J$ Otolaryngol 17: 101-102. [Crossref]

36. Marrinan EM, LaBrie RA, Mulliken JB (1998) Velopharyngeal function in nonsyndromic cleft palate: relevance of surgical technique, age at repair, and cleft type. Cleft Palate Craniofac J 35: 95-100. [Crossref]

37. Trichet C, de Buys Roessingh AS, Herzog G (2010) Labio-palatal clefts: speech therapy guidance within the multidisciplinary team. Pediatrics Archives 17: 790-799.

38. Karling J, Henningsson G, Larson O, Isberg A (1999a) Comparison between two types of pharyngeal flap with regard to configuration at rest and function and speech outcome. Cleft Palate Craniofac J 36: 154-165. [Crossref]

39. Karling J, Henningsson G, Larson O, Isberg A (1999b) Adaptation of pharyngeal wall adduction after pharyngeal flap surgery. Cleft Palate Craniofac J 36: 166-172. [Crossref]

40. Brothers DB, Dalston RW, Peterson HD, Lawrence WT (1995) Comparison of the Furlow double-opposing Z-platoplasty with the Wardill-Kilner procedure for isolated clefts of the soft palate. Plast Reconstr Surg 95: 969-977. [Crossref]
41. Barone CM, Shprintzen RJ, Strauch BS, Sablay LB, Argamaso RV (1994) Pharyngeal flap revision: flap elevation from a sacred posterior pharynx. Plast Reconstr Surg 93: 279-284. [Crossref]

42. Broome M, Herzog G, Hohlfeld J, Roessingh ADB, Jaques B (2010) Influence of the primary cleft palate closure on the future need for orthognathic surgery in unilateral cleft lip and palate patients. J Craniofac Surg 21: 1615-1618. [Crossref]

43. Ahl R, Harding-Bell A, Wharton L, Jordan A, Hall P (2016) The Buccinator Mucomuscular Flap: An In-Depth Analysis and Evaluation of Its Role in the Management of Velopharyngeal Dysfunction. Cleft Palate Craniofac J 53: 177-184. [Crossref]

44. Barot LR, Cohen MA, Larossa D (1986) Surgical indications and techniques for posterior pharyngeal flap revision. Ann Plast Surg 16: 527-531. [Crossref]

45. Witt PD, Myckatyn T, Marsh JL (1998) Salvaging the failed pharyngoplasty: intervention outcome. Cleft Palate Craniofac J 35: 447-453. [Crossref]

46. Long RE, Semb G, Shaw WC (2000) Orthodontic treatment of the patient with complete clefts of lip, alveolus and palate: lessons of the past 60 years. Cleft Palate Craniofac 37: 533.

47. Good PM, Mulliken JB, Padwa BL (2007) Frequency of Le Fort I osteotomy after repaired cleft lip and palate or cleft palate. Cleft Palate Craniofac J 44: 396-401. [Crossref]

48. Stock NM, Feragen KB (2016) Psychological adjustment to cleft lip and/or palate: A narrative review of the literature. Psychol Health 31: 777-813. [Crossref]

Copyright: (C2020 Roessingh AB. This is an open-access article distributed under the terms of the Creative Commons Attribution License, which permits unrestricted use, distribution, and reproduction in any medium, provided the original author and source are credited. 